\title{
Can Education Achieve Social Cohesion? Challenges for Kenya's Education Sector in Attaining the Social Pillar of Vision 2030
}

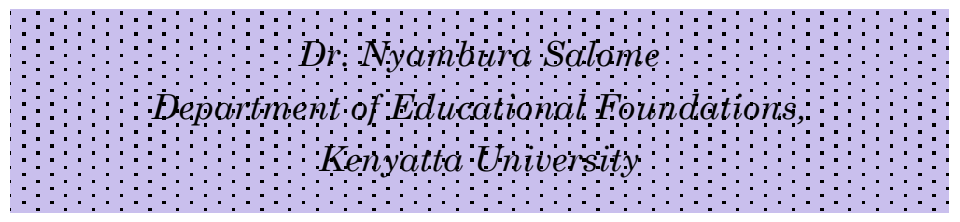

\section{Abstract}

Education is considered critical in the development of a nation towing to its role of transmitting knowledge, skills and competencies. The question of whether education can promote social cohesion has and continues to be debated all over the world. The UNESCO commission (1996), identified one of the critical pillars of education for the 21 $1^{\text {st }}$ Century as 'Learning to live together.' Indeed the demand to achieve this has been heightened by globalization, which has rendered spatial boundaries void. In Kenya, the quest for social cohesion is bedevilled by political gimmicks that perpetuate ethnocentrism and often times lead to civil strife as was evident during the post-election violence (PEV) in 2007. As a result of this, the National Cohesion and Integration Act of 2008 was passed as part of Agenda IV reforms under the National Accord Reform Agenda. This led to the formation of the

National Cohesion and Integration Commission (NCIC) 
whose mandate is to facilitate and promote equality of opportunity, good relations, harmony and peaceful coexistence between persons of different ethnic and racial backgrounds in Kenya and to advice the government thereof. This paper explores the role education can play in building social cohesion, especially in the period after PEV. Using personal experiences as an educator, I shall challenge the status quo in an attempt to chart the way forward for educators to contemplate as they strive to achieve national cohesion, which is a prerequisite to the attainment of Vision 2030.

\section{Introduction}

The sporadic electoral violence witnessed in Kenya in 1992, 1997 and 2007 highlighted the divisions amongst Kenyan ethnic communities. In 2007, thousands of people were killed while over 650, 000 were displaced. In 2003, a global poll had found Kenya to be 'the most optimistic nation' as the country welcomed a new leadership after 24 years of what the majority considered a dictatorial era. During this time, national cohesion seemed to be its peak. Then four years later, the country was 'burning', with communities hunting each other down as killings and massive destruction of property spread across the country. How did an opti- 
mistic and cohesive nation fall apart in four short years? Or had the cohesion and optimism been just a facade?

In the collective soul-searching and intense public debate that ensued, it became evident that the ties that presumably bound us as a nation were not firm. Several scholars have blamed it on a colonial legacy that perpetrated ethno-politics coupled with underlying issues such as poverty, youth unemployment, unequal access to land and resources, historical injustices and cynical exploitation of supposed ethnic 'differences' by politicians (Ogot, 1996; Kamungi, 2001; Klopp, 2001). Nonetheless, it became evident that the ethnic tension was real and that a profound level of distrust and fear exists between most of the 42 ethnic groups that make up the Kenyan population. Most citizens seem deeply ignorant of one another's histories and cultures, and have erected imaginary walls between ethnic communities, making it easier for opportunists such as politicians who retreat into their ethnic enclaves during electoral years.

The electoral violence also inadvertently triggered a series of cases of violence across the country. School vandalism resurfaced, with more 
wanton destruction of property (Shaw, 2009), interethnic violence and cases of suicide are on the increase. There have been waves of terroristic attacks and killings of security personnel (for instance in Baragoi in 2012). More worrying is the eruption of what is feared to be inter-religious conflict in some parts of the country. Indeed a culture of violence has beset the country. It is imperative to evaluate the efforts being undertaken to promote cohesion and a culture of peaceful coexistence.

My argument in this paper is that we need to reflect on and rethink our education system and the role it plays in building a cohesive nation. When rowdy schooling (schooled?) youths took to the streets throwing stones, waving machetes, carrying out wanton destruction, splitting throats of those who did not belong to their ethnic communities, it is apparent that the school had not equipped them with skills to counter the calls for violence and to beware of social responsibility as a prerequisite for nationhood. We need to critically examine the goals of our education system, right from Independence. We need to integrate the reports from all the education commissions of inquiry. We also need to look at the status quo in schools - are students and teachers promoting social cohesion or are they 
themselves divided into ethnic cocoons?

This paper is based on a historical and theoretical exploration of key aspects that impede or contribute to social cohesion in Kenya. By integrating personal experiences as an educationist for over a decade, the paper will propose strategies that Kenyan educators need to undertake to promote social cohesion in schools and thus contribute to the achievement of the social pillar of Vision 2030.

\section{Background}

After independence in 1963, the Kenya government embarked on developing social policies to mitigate the colonial impact that had led to the marginalisation of most citizens. However, the infrastructure for marginalisation, so to speak, had already been laid. Moreover, those running the new government were products of colonial education. As a result, few changes were undertaken as an elitist system and culture of education was entrenched. There was no overhaul of the colonial education that had rendered majority of Kenyans subservient to the colonialist. English was retained as the mode of instruction and the curriculum continued to glorify the virtues of the colonial master at the ex- 
pense of African culture. Several commissions were appointed to propose changes in the education system, but unfortunately, this (formation of commissions) became an obsession of post-independence governments and very little is implemented from their recommendations.

The national goals of education are blueprints which guide policymakers. The first goal, to foster nationalism, patriotism and promote national unity, acknowledges the multi-ethnic, multi-racial and inter-religious differences that exist in Kenya. It posits that it is a paramount duty of education to help the youth acquire this sense of nationhood by removing conflicts and promoting positive attitudes of mutual respect, which enable them to live together in harmony and foster patriotism in order to make a positive contribution to the life of the nation. The extent to which our education system has contributed to creating a sense of nationhood is an issue that requires further interrogation.

\section{Initiatives by Government to Promote Cohesion}

In 2008, the key protagonists in the 2007 presidential election signed the National Accord which not only outlined power sharing between 
Mwai Kibaki and Raila Odinga but also identified key issues under what was dubbed Agenda Four. The issues under Agenda Four were considered critical in addressing the underlying causes of postelection crises, reconcile communities and mitigate against future conflicts. The promulgation of the new constitution in 2010 provided further impetus in developing social cohesion through its provisions on equality, equity, inclusion, and tolerance for diversity. The constitution creates a firm foundation for addressing the country's nationhood challenges through the provisions on national goals, values and principles, culture, and citizenship. It has an expansive Bill of Rights that places responsibility on the nation and its citizens to observe and promote cohesion and integration.

Further, the Constitution also provides immense opportunities for arresting negative ethnic tendencies that threaten peace and national cohesion in all spheres of life. It does provide an opportunity to concretise and sharpen tools, platforms and mechanisms for further consolidation of gains made in the areas of national cohesion and integration since the PEV in 2008.

The Nation Cohesion and Integration Commission (NCIC) was established under the NCIC 
Act No. 12, 2008. It draws its existence from the National Dialogue and Reconciliation Agreements that sought to provide a peaceful solution to the political impasse and violence that engulfed the country after the 2007 general elections. The mandate of the commission is to facilitate and promote equality of opportunity, good relations, harmony and peaceful coexistence between persons of different ethnic, colour, religious and racial backgrounds in Kenya and to advise the government thereof (NCIC, 2010). The commission has analysed historical injustices that fuel disputes and conflicts amongst citizens of different ethnicities as it strives to identify root causes and propose remedies to the government. NCIC has also been involved in curbing ethnic polarisation fuelled by political entrepreneurs who use hate speech in their mobilisation strategies.

The experiences of PEV also prompted the initiation of a Peace Education Programme in learning institutions by the government. The programme has provided training to over 8000 teachers, produced peace education materials and sensitised communities through campaigns on peaceful co-existence (Kang'ethe, 2012). This initiative is, however, faced with challenges such as the exam focus in our education system which ignores un- 
examinable content such as what is taught in peace education. Lack of a clear conceptual framework to monitor the success of the initiative is another challenge.

Kenya's national development plan Vision 2030 is yet another effort towards building cohesion. The vision is structured on three main pillars namely, Economic, Social and Political governance, under which projects and priority programmes have been drawn. The Social Pillar is critical for this study, because it outlines the projects and programmes that will move the country towards a just and cohesive society. It underpins the role of education as a vehicle that will drive the country towards national unity and social cohesion. In view of this, the government in 2011 appointed a taskforce whose mandate was to align the education system to the constitution and Vision 2030. The taskforce, whose report is yet to be adopted, recommended the mainstreaming of national values in the curriculum. It proposed that teachers and school administrators should be provided with skills to deal with emerging issues of national values and cohesion.

Indeed, education has often been viewed as critical to the growth, development and transforma- 
tion of society (Odhiambo report, 2012). By signing up to international agreements such as MDGs, EFA and other UN Conventions, Kenya has shown a desire to improve the quality of life of its peoples, including the realisation of social cohesion. It is important to state that though legislation is pertinent, it is not the panacea to national cohesion. It is important that the initiatives discussed above are implemented within specific timelines and with appropriate monitoring strategies.

\section{Understanding Social Cohesion}

Social cohesion is a difficult concept to define because it is multi-faceted and is a quasi-concept (Beavais \& Jenson, 2002). It is best defined based on the context, culture and the time frame. For instance, social cohesion in the USA would entail the shared idea of the 'American way of life' and the civic values of the constitution, while in most African countries, the concept of 'ubuntu' underpins key aspects of the concept. In terms of time frame, the foundations of social cohesion have shifted from the $19^{\text {th }}$ and $20^{\text {th }}$ century understanding of 'assimilation' of peoples of diverse religions, ethnicities, and social groups into a $21^{\text {st }}$ century understanding of being 'accommodating' of others. 
Early sociologists such as Emile Durkheim, Auguste Comte and Herbert Spencer agonised about the society in the advent of industrialization. Durkheim was the first to use the concept of social cohesion, which he described as an ordering feature of a society. He further described it as the interdependence between the members of a society, taking into account their shared loyalties and solidarity as a community (Durkheim, 1956). Other scholars have variously defined and described the term Dahrendorf et al. (1995) contends that a socially cohesive society is one that prevents social exclusion, offers opportunities to all its members within the framework of accepted values and institutions. Wooley (1998) on the other hand, distinguishes the following issues as characteristic of a socially cohesive society:

- Absence of social exclusion

- Interactions and connections based on social capital

- Shared values and communities of interpretation based on group identity.

- Berger-Schimtt (2000) identifies two dimensions of social cohesion: 
- The reduction of disparities, inequalities and social exclusion

- The strengthening of social relations, interactions and ties.

Another definition by Green, Janmaat and Han (2009) notes that social cohesion is the property by which whole societies and the individuals within them are bound together through the action of specific attitudes, behaviour, rules and institutions which rely on consensus rather than pure coercion. By including the aspect of coercion they note that, it distinguishes those communities under which the members are coerced to sustain the bond and thus their co-existence is deprived of harmony.

The Delors' UNESCO report on Education a Treasure Within anticipated the challenges of the $21^{\text {st }}$ century and in their report, conceived essential pillars of education for this century, two of which are significant for this study: 'Learning to be' and 'Learning to live together' which underpins the fundamentals of ties that bind a community together a people who are aware of their strengths and limitations, while at the same time acknowledging the 'other' and being willing to co-exist with them. We shall discuss these two pillars in the next section. 
In the African perspective, the African philosophical worldview, as expressed in the Zulu proverb, 'Umuntungumuntungabantu' (A person is a person because of people) also highlights the significance of 'being' that is defined by the 'other', thus emphasising that a person in society is only defined by his relationship and interaction with others - be they from his community or not. In West Africa, the commonly used concept is 'abusua' which denotes the familial relations critical in any society - that go beyond kinship ties.

The NCIC acknowledges that Kenya is a multi-ethnic society made up of over 42 ethnic groups and other peoples who include the different races and refugees. It thus defines social cohesion as referring to a society whose values are harmonious and non-discriminatory for peaceful coexistence and integration between persons of the different ethnic and racial communities of Kenya

In summary, the above definitions underpin the following indicators of social cohesion: shared values, sense of a common identity, trust and loyalty, communities of interpretation, sense of belonging, inclusivity, equality of opportunities, equity, participation, tolerance for cultural diversity, 
shared national heritage, active civic participation and law abiding. These indicators can be measured from a micro-level of the individual and family to the macro-level where we examine the essence of cohesion in a community, county, country and on the global stage.

\section{The Role of Education in Social Cohesion}

The role education plays in building social cohesion has been interrogated and debated in political, citizenship, and peace education discourses more so as different countries aspire to become stable democracies. Kyungu (1999) contends that schools are expected to be places where growth and development of the individual occurs. They are agents of developing cohesion, change, liberation and conservation of what is considered to be the norms of the society. Dominant discourse on schools portrays them as a natural product of the values, capacities and rights of a people. However, as Brown (2003) contends, these spaces are structurally embedded in and historically constituted through dynamic, post-industrial, global, economic and political relationships. Abagi and Otieno (2000) aver that the role schooling plays in promoting the achievement of social goals has been focused on 
how learners perform in national exams in terms of marks obtained taken as a proxy of achievement. This is not a relevant measure since there are great disparities and disjuncture between schools.

In Kenya, during the euphoric years after independence, education was seen as being able to not only create skilled personnel but also national cohesion (Kiernan, 2000). However, this role was marred by many challenges, such as the residue of the past education system which appealed more to the middle class rather than the traditional values that propagated community cohesiveness. Other challenges included the fact that the administrative boundaries had already been set by the colonial government and they were based on ethnic divide. This is why you find the Aberdare region is home to the Agikuyu, the Lake basin region is home to the Luo, etc. This geographical division was severed by the political leaders who focused on developing certain parts of the country while marginalising others. After decades of under-development of some regions, the politics of banality have set in whereby, majority believe that the only way for their regions to develop is to have a member of their community as a politician or the president. This has led to hostility between communities 
which are evidenced during electoral periods. Other challenges have included cultural diversity and impersonal social relations, poverty, unemployment, corruption, race and class stratification and the advent of technology whereby blogs and websites have been created to promote discord amongst the various communities.

These challenges also affect the education institutions. For instance, some schools in the marginalised communities are a sad sight. They lack even basic amenities like classrooms! Not long ago, media reports showed a school in western Kenya where students learn in a cave! Several cases of corruption in utilising school funds have been reported. Political interference in the management of education institutions is also rampant. Cases have been reported of politicians demanding for favours from schools or seeking to influence who should be promoted or appointed as the school principal (Owinyo, 2008). In rural areas, the challenges for social cohesion may not be so glaring since there will be a homogenous group, one ethnic group and similar social economic status. However, in cases where you have a minority group, for instance the business community who may be from other regions or internally displaced persons or refugees, then 
there is a high likelihood that this group may be discriminated. Certainly, all these impact on the students and undermine efforts to promote social cohesion.

\section{Way Forward}

To cultivate national cohesion through education, it is futile, as Mbembe (2001) observes, if we thought we can achieve this by looking back to our pre-colonial histories. Indeed, as Diouf (2005) demonstrates, the African youth do not even feel they are heirs of national independence or development; they feel even less the need to restore the personality and historicity of African societies. Thus, the challenge for educators is to construct an education system that will address the social realities of the contemporary society, with its ambivalences; an education system that will withstand the forces of globalisation and the hegemonic order, perhaps by developing new and imaginative ways of enabling people to understand their situation, control and direct change rather than being controlled and directed by it. It should be a system that will be able to grasp some aspects and values of African tradition, an education capable of propagating an African identity which is based on the current multi- 
plicity and temporality of its context. This education ought to be able to give up archaic colonial mentalities, seek to be inclusive and challenge new ideologies before adopting them.

Demack et al. (2007) suggests that the contributions of schools to the cohesion agenda should be manifest in certain areas. These are discussed below.

\section{Teaching, Learning and Curriculum}

This has to do with helping students learn to understand others, to value diversity while also promoting shared values. The Kenya education system has to some extent enabled this process by offering relevant content in the subjects of History, Social Studies, Religious Studies and Geography. These subjects have units on the different peoples of Kenya, their location, religion, livelihood etc. This enables students to appreciate the diversity of their country. There is also a quota system in the enrolment of students, especially in high school. County schools are required to enrol a certain percentage of students from other counties. Teacher employment also advocates for deployment of teachers in various counties in the country. This 
movement enables them to be open to the various communities their students come from. In primary school, there is a requirement for students in different classes to visit different parts of the country depending on the curriculum. This gives them an opportunity to experience other communities.

However, our education system is still lacking in promoting social cohesion. Thus, when the most recent education commission by Odhiambo (2012) proposes mainstreaming national values and cohesion across the education system, this should not only be in the content - whereby curriculum developers pay attention to inclusive representation in the teaching and learning materials, for instance by ensuring names of persons from the Ogiek community (one of the marginalised communities in Kenya) will stand alongside those of the Kikuyu and even the Aweer of Lamu. They also need to ensure the following critical aspects of education are implemented in the system:

- Learning to be is of great significance and is a prerequisite for co-existence in a multi-ethnic and multi-racial community such as Kenya. The students should be taught self-awareness and self-appreciation. This builds confidence 
amongst them, as they are encouraged to be creative, innovative and autonomous. They should also be taught the rules that govern personal behaviour, so that they can appreciate their own being, that of others and also personal responsibility.

- Learning to live together is also of great essence. All schools, whether private or public, should be multi-cultural centres, where students will meet people from other communities. They should learn about the perspectives of other ethnic, racial, religious and social groups. The schools should develop projects that will embrace the richness of each community. For instance, the drama and music festival is a good opportunity for students to interact, learn from each other and appreciate cultural and ethnic diversity. Emphasis here should be on the rules that govern personal, interpersonal and political action.

This underpins the social and legal principles that govern good citizenship, obligations of political leaders, behaviour expected of citizens, and consequences for not adhering to these principles. Schools can also facilitate a student's appreciation 
for the complexity of issues related to historical and global current events and, in so doing, may increase the likelihood that a student will learn to appreciate a point of view other than his or her own. The schools should also initiate debates on communal narratives and histories by interrogating the true and doctored histories and realities of their communities. This would build critical minds among students and thus promote autonomy when it comes to political manipulations.

\section{Experiential Learning}

In this, focus should be given to the hidden curriculum, where teachers, school administrators, and neighbours of the school should be keen on portraying behaviours that are aligned to the principles of good citizenship, since students usually model what they see around them. A recent study report in the media indicated that pupils in primary schools are aware of their ethnicities and that some are cautioned by their parents not to play with children from other ethnic groups. If teachers segregate themselves in camps based on their ethnicity, then they do inadvertently promote similar tendencies among the pupils. In other cases, the use of vernacular also delineates minority students 
especially in rural areas. Indeed, the schools should aim at providing an experience roughly consistent with those citizenship principles embedded in the constitution; in effect, decreasing the distance between individuals of different communities.

The educational experience derives from a wide variety of activities, whether in the classroom, corridors, schoolyard, playing field, or school bus. Thus the degree to which a school may do this well depends on its ability to design the hidden curriculum, its culture, and the social capital of its surrounding community. The school should encourage debate clubs, music and drama, and direct engagement with community leaders from different backgrounds. For instance, the students could discuss Chapter 6 of the constitution on integrity, thus keeping them in touch with the discourse in society. The schools should set aside sufficient time and opportunity in their curricula to introduce young people to collaborative projects within the school and which have a relation to the community and larger society. This can be achieved through analysis of stories, role plays and real life situations. An important benefit of such experiences at school is that the students are able to learn methods of resolving conflicts. This provides them with a valuable source 
of reference in later life.

\section{Equity and Excellence}

School policies should be geared at providing equality and equity to all. The personal needs of learners should be known by the teachers and administrators who should strive to address these needs - for instance hunger, stress due to a dysfunctional family and all forms of harassment. A Nairobi school principal once shared that she only got to know that there were students in her school who never had any lunch, when she walked into a classroom one day and found some pupils sleeping on the lockers during lunch hour. The class teacher had never been aware of this, and the other pupils only ignored their peers. It is essential for schools to promote communality, which promotes love, care for one another in spite of class, ethnic, racial or religious diversity. School systems are expected to provide an equality of opportunity for all students. If the public perceives that the school system is biased and unfair, then the trust citizens place in various other public institutions is compromised. For instance, the willingness of adults to play by the rules of the game may be compromised if fair-

ness in the system appears suspect. For instance, if 
teachers are divided in ethnic cocoons, parents of minority students will witness the discriminatory practices against their children. Thus, schools need to be in touch with the laws and policies of the country; teachers should be at the forefront to promote and interrogate these policies. In my graduate class on Social Policy, I was always been surprised that my lecturers were unable to interact with any of the education policies. The excuse was that the documents were a reserve of the school principal.

The education system should ensure there are equal opportunities for all citizens to succeed at all levels of education. The Bill of Rights and Chapter 6 of the Constitution should be implemented to the letter. The new constitution provides means to eliminate the variations that exist between schools in the counties. One of these is a centre for excellence in each county. This will go a long way in providing quality education to brilliant but needy students. By bridging the gaps between the different communities, races and social classes, schools thus participate in establishing the indicators we mentioned earlier on cohesion. 


\section{Engagement and Outreach Services}

Schools do not only provide space for students from different communities to interact; they also create avenues for parents and the larger community to meet. These interactions develop positive social relations, which are critical for co-existence. The community should not be only engaged with the school when they are receiving tenders or in providing casual labour. The schools should engage the community through seeking out role models to give motivation talks to the pupils. They should also engage professionals, alumni and business people in providing services to the school. The school should also be privy to projects they can support in the community, for instance visiting the elderly and cleaning up the town.

The choice of community members should be done objectively; the individuals picked should be open minded and inspiring to the students. The teachers should strive at creating a forum to engage the community in order to bridge the gap that exists between schools and the surrounding community. For instance, several years ago I undertook a research in a rural school where the teachers were always in conflict with the community whom 
they accused of supplying drugs to the students. This conflict led to hostility between the school and the community such that when the students went on strike and caused wanton destruction of the school, the community members cheered (Owinyo, 2008). This would not have occurred if the school engaged the community in promoting social cohesion. It is thus imperative for schools to create dialogical spaces where the surrounding communities can interact and bridge the spatial differences amongst themselves. An example is the work of Children Peace Initiative-Kenya that works in Northern Eastern to bring together pupils and teachers from warring communities to discuss the underlying causes of conflicts in the region. The parents are later brought on board to witness their children relating in music and sports with children from the 'other' community. This initiative provides a forum for parents to re-examine their prejudices about others.

\section{Systems of Monitoring and Evaluation}

There is need to establish systems to monitor and evaluate implementation of the social cohesion agenda in educational institutions. The $\mathrm{MoE}$ should measure the extent to which schools have 
created, implemented and sustained the interests and objectives of all the ethnic communities represented in the county. The diverse views from all the ethnic communities should be considered and where differences of conflicts arise, the modes of resolution should be clarified by the school board. Ethnocentric tendencies and discourses should be discouraged. For instance, ethnic associations in institutions should be dispensed with and perhaps in their place have county associations which in higher education may serve as a forum for discussing the challenges facing particular counties. Class teachers and even subject teachers need to be sensitised on the need to promote social cohesion during their teaching. They should be made conscious of the effects the ethnic examples they use in class can negatively affect students. Any grouping based on ethnicity, class, gender or any other aspect should immediately be recognised and corrected before it causes more divisiveness. A school in Nairobi discovered that its pupils were divided based on the type of cars their parents owned. Students whose parents owned fuel guzzlers were highly respected and only associated with those of their class. A girl whose father owned an old Volkswagen cried every morning she was dropped at school; she became withdrawn and her performance dropped. 
When interrogated, she said it were better if she walked to school than have her peers laugh at her father's old car. Such cases exist in our schools. But are teachers aware and how long does it take for them to recognise them? If proper systems of monitoring are put in place, teachers will be sensitised enough to promote the values of social cohesion as earlier discussed.

\section{Public Support and Consensus}

The success of schools in creating and sustaining cohesion is based in part on their ability to garner public support and consensus, and hence their ability to adjudicate differences over educational objectives. If an education institution only attracts students from one social class or from a particular ethnic or racial community, it will fail in promoting the social cohesion discourse. The gap between public and private schools has raised concerns and divisiveness in the recent past and even affected the youths. When I enrolled my daughter in a public secondary school in Nairobi, the first question her roommate asked was whether she had been in a private or public primary school. Apparently, the other girl had been in a private school and when my daughter said she had been to a pub- 
lic school, her peer showed indifference. A boundary had already been established in terms of presumed class status and intellectual ability. We must be conscious of divisive practices in schools. Policies should be implemented to ensure all educational institutions are inclusive with respect to gender, ethnicity, race, and class. Educational institutions need to lead on social cohesion. Awards should be given to schools that promote these values. This way, such schools will attract more public support.

\section{Conclusion}

This paper discussed a critical aspect of the Social Pillar in Kenya's Vision 2030. Without social cohesion, achieving the other pillars will remain an illusion. As a fundamental socializing agent, the school plays a critical role in establishing social cohesion. We have alluded to the fact that the school system has a positive and negative or hidden face in its role, whereby besides promoting the skills, values and competencies needed, it also inadvertently perpetrates stratification and divisiveness. This is why a discussion on the role the school plays in promoting the social cohesion agenda is important. Such a discussion brings forth hidden practices within the school that undermine cohesion. 
When students from different ethnic communities are civil to each other at school, does this translate to the same behaviour out of school? Would it translate to the same in the context of a crisis such as PEV? We need to engage amongst ourselves on the relevant indicators of cohesion in society. We need to be proactive in enabling the development of cohesion right from early childhood. Education should strive at propagating the changes needed in society, since it is a central biography of individuals that influences their life chances and choices. If we desire peaceful general elections by 2030, we must invest in establishing and developing social cohesion in schools.

According to Freire (1985), a good education system should promote a critical pedagogy in which school administrators, teachers, students and the larger community are continuously critical, reflective, questioning and challenging the various webs of actions, desires and subjectivities which are effected through politics, economics, education, culture and external systems of inequity which promote discord amongst the peoples. Through this process they are able to challenge the corrosive ideologies and stereotypes and instructional practices that constrain the possibilities for cohesion. Lei- 
styna (2003) notes that only through a critical pedagogy that is more inclusive and historically situated and one that engages a critical public debate that educators can better understand the complex roots of colonialisation, injustice, corruption, inequality and violence in the contemporary society and thus better inform themselves of the current socio-cultural context in which students live as well as the tools they will need to become aware, active and responsible citizens and critical agents of change in the quest for social cohesion and integration. 


\section{References}

Abagi, O. \& Otieno, W. (2000). Counting the social impact of schooling: What Kenyans say about their school system and gender relations. Nairobi: IPRA.

Beauvais, C. \& Jenson, J. (2002). Social cohesion: Updating the state of research. CPRN Discussion Paper No.F/22, Canadian Policy Research Network, Ottawa.

Berger-Schmitt, R. (2000). Social cohesion as an aspect of the quality of societies: Concept and measurement. EuReporting Working Paper No. 14 Mannheim.

Brown, E. (2003). Freedom for some, discipline for 'others': The structure of inequality in education. In Saltman, K. \& Gabbard, D. (eds.). Education as enforcement: The militarization and corporatization of schools. New York \& London: Routledge-Falmer.

Dahrendorf, R. et al. (1995). Report on wealth creation and social cohesion in a free society. London: Commission on Wealth Creation and Social Cohesion.

Demack, S. et al. (2010). Young people and community cohesion. Analysis from the longitudinal study 
of young people in England (LSYPE). Centre for Regional Economic and Social Research and the Centre for Educational Inclusion Research

Diouf, M. (2005). Afterword. In Honwana, A. \& De Boeck, F. (eds.). Makers and breakers: Children and youth in post-colonial Africa. Oxford: Currey

Durkheim, E. (1956). Education and sociology. Translated by S.D. Fox. New York: The Free Press.

Freire, P. (1985). The politics of education: Culture, power and liberation. Massachusetts: Bergin \& Carvey.

Green, A., Janmaat, J. \& Han, C. (2009). Regimes of social cohesion. Centre for Learning and Life Chances in Knowledge Economies and Societies. Available at: http//www.llakes.org.uk.

Kamungi, P. (2001). The current situation of Internally Displaced Persons in Kenya. Nairobi: Jesuit Relief Services.

Kang'ethe, M. (2012). Kenya Ministry of Education Work on Education and Peace. Nairobi: Global Peace Campaign Network.

Government of the Republic of Kenya. (2007). Kenya Vision 2030. The Popular Version. Nairobi: Government Printer. 
Kiernan, M. (2000). The role of donors in educational reconstruction and transformation. In Mebrahtu, T. \& Crossley, M. (eds.). Globalisation, educational transformation and societies in transition. Oxford Studies in Comparative Education, 10(2), 195-201.

Klopp, J. (2001). Ethnic clashes and winning elections: The case of Kenya's electoral despotism. Canadian Journal of Africa Studies, 35(2), 16-35.

Kyungu, S.M. (1999). Leadership and discipline: The role of prefects in schools. Paper presented at the National Conference on Student Leadership, Delinquency, Guidance and Pastoral Care in Schools. Kenyatta University.

Leistyna, P. (2003). Facing oppression: Youth voices from the front. In Saltman, K. \& Gabbard, D. (eds.). Education as enforcement: The militarization and corporatization of schools. New York \& London: RoutledgeFalmer.

Mbembe, A. (1992). Provisional notes on the post colony. Africa 62, p. 1 National Cohesion and Integration Commission. Annual Report 2009-2010. Available at: www.cohesion.or.ke

Odhiambo, D. (2012). Taskforce report on the alignment of the education sector to the constitution of Kenya 2012. Nairobi: Ministry of Education. 
Ogot, B. (1996). Ethnicity, nationalism and democracy. A kind of historiography. In Bethwell, A. Ogot (ed.) Ethnicity, nationalism and democracy in Africa. Maseno: Institute of Research and Postgraduate Studies.

Owinyo, N. (2008). Caught in-between: Exploring the complexities of school vandalism. Nairobi: Paulines Publications Africa.

Shaw, G. (2009). Reporting on peace education conference in Kenya. Available at www.npi.org

UNESCO. (1996). Learning-The treasure within. Report to UNESCO of the International Commission on Education for the Twenty-First Century. Paris: UNESCO

Woolley, F. (1998). Social cohesion and voluntary activity: Making connections. Paper presented at the conference, The State of Living Standards and the Quality of Life, Centre for the Study of Living Standards (CSLS), October 30-31, 1998, Ottawa, Ontario/Canada. 